\title{
Article \\ RFID Technology as a Low-Cost and Passive Way to Digitize Industrial Analogic Indicators
}

\author{
Mohammadamin Hosseinifard ${ }^{1}{ }^{*}\left(\mathbb{D}\right.$, Salam Alzubaidi ${ }^{1}$, Andrea Michel ${ }^{2} \mathbb{D}$ and Gualtiero Fantoni ${ }^{1}$ \\ 1 Department of Civil and Industrial Engineering, University of Pisa, 56122 Pisa, Italy; \\ salam.al-zubaidi@phd.unipi.it (S.A.); gualtiero.fantoni@unipi.it (G.F.) \\ 2 Department of Information Engineering, University of Pisa, 56122 Pisa, Italy; andrea.michel@unipi.it \\ * Correspondence: Mohammad.Hosseinifard@phd.unipi.it
}

check for updates

Citation: Hosseinifard, M.; Alzubaidi, S.; Michel, A.; Fantoni, G. RFID Technology as a Low-Cost and Passive Way to Digitize Industrial Analogic Indicators. Appl. Sci. 2022, 12, 1451. https://doi.org/10.3390/ app12031451

Academic Editor: Roque Calvo

Received: 31 December 2021

Accepted: 24 January 2022

Published: 29 January 2022

Publisher's Note: MDPI stays neutral with regard to jurisdictional claims in published maps and institutional affiliations.

Copyright: (c) 2022 by the authors. Licensee MDPI, Basel, Switzerland. This article is an open access article distributed under the terms and conditions of the Creative Commons Attribution (CC BY) license (https:// creativecommons.org/licenses/by/ $4.0 /)$.

\begin{abstract}
Simple analog devices like manometers, manual valves, etc., have been ignored in the digitization process that has characterized the transition towards Industry 4.0. The reason behind this is that their substitution with the equivalent digital versions is high cost and needs re-wiring. This study introduces a low-cost wireless and passive model aligned with the Industry 4.0 paradigm to digitize analog indicators. The concept is based on electromagnetic (EM) shielding of the manometer's embedded radio frequency identification (RFID) tag. We designed and tuned a new tiny RFID tag to be embedded into analog devices. Finally, a digitized manometer by RFID electromagnetic shielding concept is simulated in the Ansys HFSS modeling environment.
\end{abstract}

Keywords: tiny RFID; metallic electromagnetic isolation; analog manometer; Ansys HFSS simulator; passive digitization

\section{Introduction}

The digitization process of raw materials, semifinished and finished products, and machines play a significant role in the Industry 4.0 revolution and rely mainly on the Internet of Things (IoT) and radio frequency identification (RFID) technologies. However, many challenges related to the digitization process include and are not limited to high cost, energy consumption, and information integration. One of the digitization challenges is the design and manufacturing of analogic indicators and manometers, which take into account many industrial and engineering design considerations [1].

Analog devices like manometers, manual valves, handwheels, levers, clamps, etc., are very common on shopfloors. They are present in old machines, but also in the piping system of modern plants, e.g., in fire extinguishers and in security elements such as cage doors, etc. When integrated with old equipment and types of machinery, they are retrofitted using digital devices, switches and IoT cabled or wireless solutions, but alternatively, their monitoring is left to operators with consequent time loss, errors, etc. Sometimes, due to the slow evolution of the phenomena they monitor, they are left unread for a long time with possible consequences on safety (fire extinguishers), performance (wear and corrosion), and so on. Such oblivion is critical for the concept of completely twinning [2] the shop floor in order to be able to digitally manage the production (people and machines) in a cyber-physical way [3].

Data collection based on the passive RFID tags approach is a valuable and competitive solution for the digitization process as a low-cost, battery-less asset and has a long life compared with other techniques [4]. However, a limitation of passive RFID systems is the relatively short read range with respect to other active systems [5]. Larger read ranges can be achieved at the cost of a bigger tag antenna size, which makes the integration process into existing devices more difficult. Therefore, this study aims to simplify the digitization process considering this drawback with low costs, using enabling technologies and embedded systems for data collection in a real-time manner. The challenge is to 
design and embed small passive RFID tags inside the analog devices, keeping an acceptable reading range. Many researchers have discussed RFID limitations and challenges dealing with the environment and substances and their influences like reading range reductions and wave reflections and suggested different possible solutions [6-8]. The general concept of the methodology is based on the material behavior and its impact on the RFID system. Hence, the radio waves pass through air, plastic, wood, and ceramics efficiently, while there is a considerable reduction and reflection with other materials such as conductors (e.g., metals). The use of metals in industrial environments creates blind spots for RFID readers and disrupts their performance $[9,10]$. Covering the RFID tag with metals causes electromagnetic (EM) shielding, but a movement of the metal cover removes the isolation and turns the RFID chip on. The adverse effects of metals on RFID performance have also been investigated by Arora [11].

This work aims to digitize analog devices by integrating new tiny passive RFID tags [9]. We performed experiments in large dimensions with commercial RFID tags to evaluate the technical feasibility of the concept. A tag antenna was designed, virtually localized in an analog manometer, and numerically simulated using Ansys HFSS V2021 R2 software.

Then, the EM shielding cover was optimized, and the final digitized analog manometer performance was simulated. The following sections illustrate the state of the art, then the methodology will be explained in detail. Later, in the experiments, Ansys HFSS simulation practices and results are described, and finally, conclusions are drawn.

\section{The State of the Art}

\subsection{Potential of Wireless Networks in the Industry}

Wireless network protocols as an IoT technology are used to enable physical objects to collect and exchange data nowadays of Industry 4.0 era [12]. Wireless networks are promising for current and future industrial aspects in terms of the digital transformation of companies, especially in automating the process of logistics, asset tracking digitization, monitoring, and controls [13]. The growing influence of IoT has created great potential for increasing the share of wireless communication networks in the industry. Compiling Hardware Meets Software (HMS) team annual reports for the last seven years (Figure 1) show that the majority of industrial networks' share (approximately $94 \%$ ) is related to industrial networks with cable platforms such as Fieldbus and industrial Ethernet [14]. However, the wireless network graph has constantly been rising, from about zero percent in 2015 to $7 \%$ in 2021. This trend illustrates a clear picture of the future position of wireless networks in the industry.

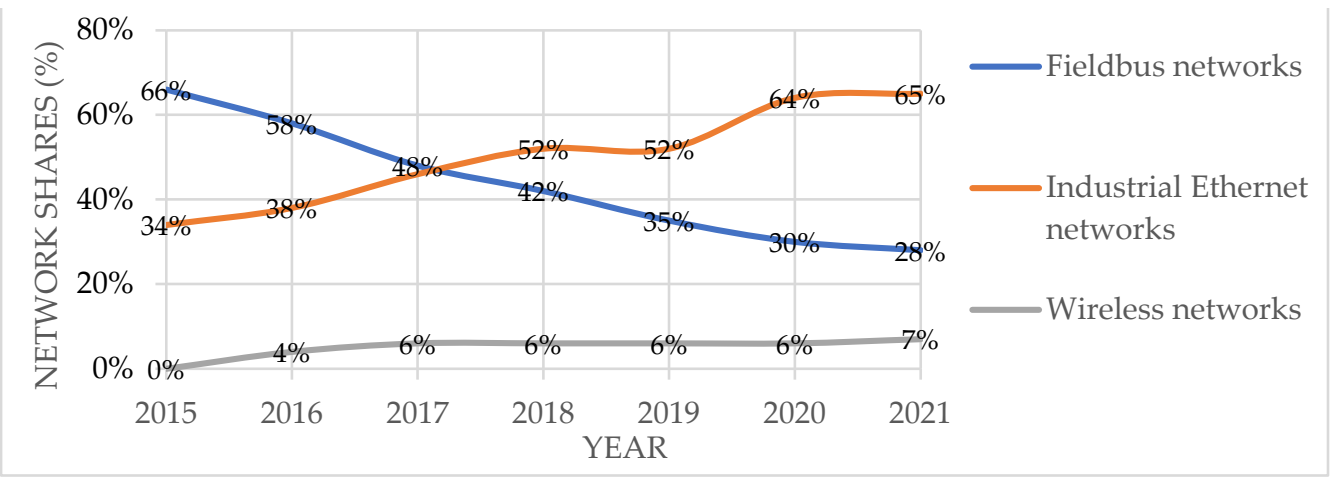

Figure 1. Industrial networks' market shares.

In [15], the authors merged the wireless network and RFID technology to manage the production line in a traditional manufacturing laboratory to avoid errors due to the manual recording, remotely monitoring the manufacturing process via the internet, and evaluating the workers' progress. In [16], authors proved that the transmission speed, low energy consumption, and a higher number of devices could be simultaneously operated using a 
wireless network. Furthermore, when discussing IoT applications in industry, we found the acronym IIoT that stands for Industrial IoT and that it is building a new domain with respect to IoT in everyday products. All the considerations mentioned above demonstrate that passive RFID could be a promising solution for digitizing analogical devices.

\subsection{Embedded Passive RFID Tags}

Passive RFID tags are increasingly used to automate systems, identify products, trace assets, monitor, measure the process, and control their physical parameter [17]. But embedding passive RFID tags requires many considerations related to the RFID itself, the object or systems, and/or the space that contains the RFID [18]. In [19], the authors explained the importance of the RFID tag design parameters in terms of size, shape, configuration, the material of the antenna and chip, and the objects that RFID tags install on or are embedded. The RFID tag design parameters are essential, so embedding passive RFID tags in the analog indicators and manometers is a practical challenge and potential research area. Digital transmitters could replace these manometers, but safety standards emphasize the need to keep them as redundancies for analogical ones. These restrictions ensure that operators/supervisors can monitor critical parameters such as boiler temperature and pressure in both methods, on-site/physically and in an automation system/digitally [20]. In this regard, the purpose of our practical application is to digitize hotspots and trigger points in an analog manometer passively and wirelessly.

Moreover, many industrial environments present "ATmosphere EXplosive" areas where digital devices have to follow particular restrictions and their ATEX certified versions have a higher cost than the standard ones.

\subsection{Electromagnetic Isolation}

The EM isolation between transmitter (RFID reader) and receiver (RFID tag) is a critical problem in a pulse-modulated RFID system, where transmitter and receiver use identical frequencies [21]. Metals can create blind spots in RFID reading zones by completely reflecting high-frequency EM waves [22]. These blind spots cause signal interruption and receiving signal strength indicator (RSSI) variations [23]. RSSI assesses the attenuation of a received signal with respect to the source. The value of this parameter is always negative, and numbers closer to zero indicate better power and quality of the network [24]. Therefore, embedding the passive RFID tags in the analogic devices will be affected by the composed material of the devices, especially when the cover is made of metallic components. The isolation of passive RFID tags from EM waves transmitted from the RFID reader is not always a disadvantage, especially when the physical parameters required are not continuously varied. So, the metallic interaction could play an essential role in RFID isolation from the reader whenever needed in an automatic mode, and the passive RFID tags could be detected whenever the metallic cover is (re)moved. This dynamic scenario supported by the facts mentioned in the paragraphs above shall guide us to the main research questions:

- Can RFID technology digitize the measurement process of analogic devices?

- Are passive RFID tags appropriate to be embedded in the analogic systems collecting the data wirelessly?

The following sections will clearly answer and explain how RFID technology can support the digitization of the measurement process of analogic devices.

\section{Materials and Methods}

Passive RFID tags, due to the lack of internal power supply, are dependent on the energy absorption sent from the RFID reader antenna, making the tag's performance highly linked to the environment and the installation location. For this reason, the RFID must be tuned precisely for its installation substrate (analog manometer) then simulation must be performed for all RFID tag, substrate, and metallic cover parameters [25,26]. For this reason, the research methodology is divided into three sections. 
- Experiment and conceptual test;

- Design and tune a new RFID tag;

- Electromagnetic isolation cover simulation and optimization.

The study methodology started with modeling EM isolation effects on commercial RFID tags [26]. Due to the large dimension of general purpose RFID tags (a few centimeters), a test bench was designed on a large scale. Modeling was done to test the initial concept and determine the influential variables. In the second part, an analog manometer is introduced as one of the possible applications to be digitized with this method. A tiny RFID tag was designed and tuned to be implanted into the analog manometer. Finally, we execute a compound EM simulation to validate the analog manometer digitization concept for the embedded RFIDs, manometer, and metallic cover.

\subsection{Experiment and Conceptual Test}

The general idea was to design a bench test based on covering the RFID tags with different metal plates. Circular openings with various radiuses were manufactured in metal plates that allow electromagnetic waves to pass through. The RFID tag was slowly moved towards or backward of the isolation area by rotating the metallic sheet, thus examining the effect of changing the amount of EM isolation in RFID tags. The operating frequency of UHF RFID was in the range of 860 to 930 Mhz. The size of the smallest RFID tag was $44 \times 44 \mathrm{~mm}$, therefore, the smallest size of the circular window was set to $40 \mathrm{~mm}$, while the largest size of the circular window to $80 \mathrm{~mm}$, which corresponds to about $\lambda / 4$ at $900 \mathrm{MHz}$. The EM waves emitted from the RFID reader antenna charge the tag antenna, and the absorbed energy turn on the tag chip by moving the cover. A stepper motor drives the shielding cover with an accuracy of $3^{\circ}$ degree of rotation per step. The stepper motor was driven in half-step mode by a 4ZeroBox (a microcontroller unit suitable for industrial applications) and controls the metallic cover [27]. The measurements were performed by a CAEN UHF RFID reader model R4300, and the data was sent to the computer through the serial port (Figure $2 \mathrm{a}$ ). The reader was connected to a $9 \mathrm{~dB}$ linearly polarized antenna by SMA adapters and a 20 foot RG-58 cable with $1 \mathrm{db}$ per 10 feet loss in the $900 \mathrm{MHz}$ frequency range. According to Figure $2 \mathrm{~b}$, the metal cover moved from position 1 in steps of $3^{\circ}$ to position 2, so that half of the tag was exposed to EM waves, then moving from position 2 to 3 caused the entire surface of the tag antenna to be uncovered. The same pattern was repeated in positions 4 and 5 , and the whole surface of the tag antenna was to pass from covered to uncovered and vice versa.

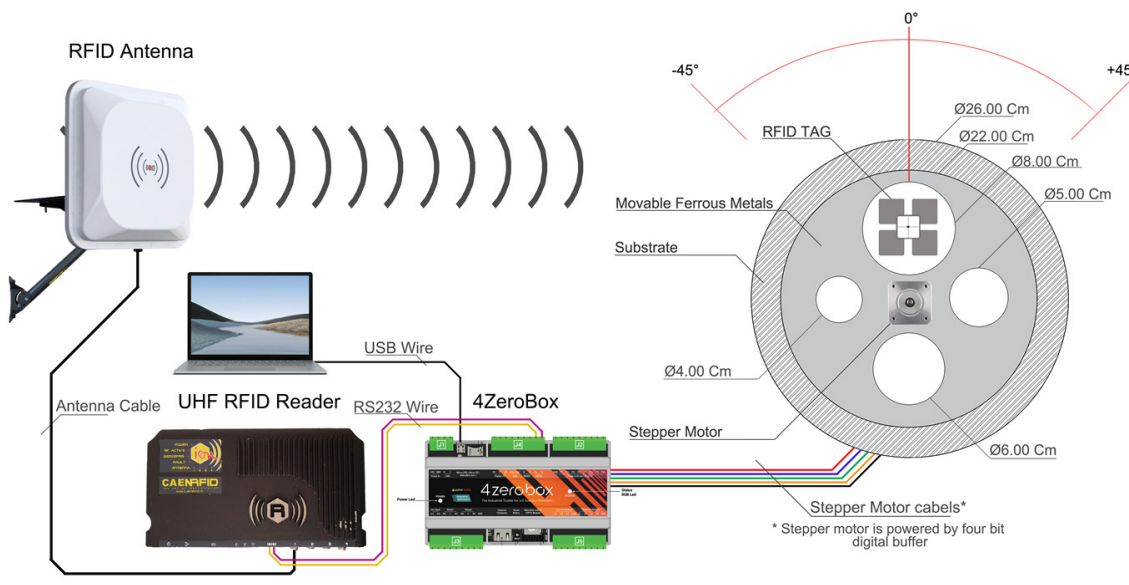

(a)

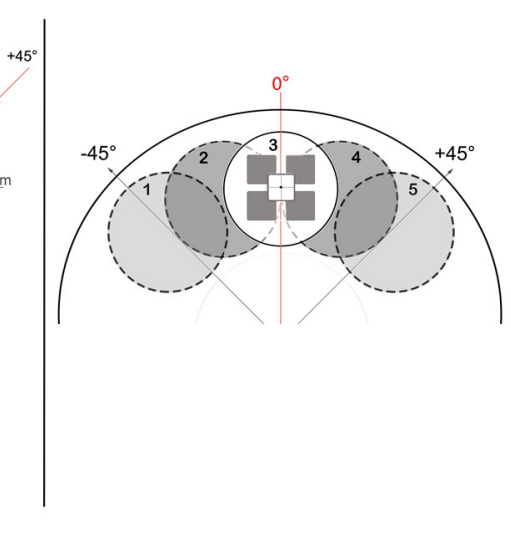

(b)

Figure 2. Test bench design and covering process.

RSSI measurements were performed in 1080 samples for three different RFID tags and three different metal covers. The passive tags specifications are given in Table 1 . The 
chips used in the RFID tags belong to the same family, but the structure and design of their antennas were entirely different and designed for various purposes.

Table 1. Passive tags specification.

\begin{tabular}{|c|c|c|c|c|c|c|}
\hline RFID Passive Tag & Protocol & Chip Type & $\begin{array}{c}\text { EPC } \\
\text { Memory }\end{array}$ & $\begin{array}{c}\text { User } \\
\text { Memory }\end{array}$ & Antenna Size & Read Range \\
\hline $\begin{array}{l}\text { True 3D QTTM } \\
\text { Long Reading }\end{array}$ & $\begin{array}{l}\text { ISO/IEC 18000-6C } \\
\text { (class } 1 \text { Gen2) }\end{array}$ & $\begin{array}{c}\text { Impinj } \\
\text { Monza-4QT QTTM }\end{array}$ & 128 bits & 512 bits & $72 \times 72 \mathrm{~mm}$ & $10-12 \mathrm{~m}$ \\
\hline Impinj h47 & $\begin{array}{l}\text { ISO/IEC 18000-6C } \\
\text { (class } 1 \text { Gen2) }\end{array}$ & Impinj Monza 4E & 496 bits & 128 bits & $44 \times 44 \mathrm{~mm}$ & $6-7 \mathrm{~m}$ \\
\hline Impinj Monza 4D & $\begin{array}{c}\text { ISO } 18000-6 C, \text { EPC } \\
\text { Class } 1 \text { Gen } 2\end{array}$ & Impinj Monza 4D & 128-bit & 32-bit & $86 \times 24 \mathrm{~mm}$ & $8-10 \mathrm{~m}$ \\
\hline
\end{tabular}

\subsection{Design and Tuning of RFID Tags}

The commercial tags' large dimension increased the modeling test bench size and made it impossible to implement the concept directly in practical applications. Therefore, an RFID tag was designed and simulated with the priority of keeping the antenna dimensions so limited that they could be embedded in an analog manometer. The proposed solution, shown in Figure 3, is based on creating an EM shield for the RFID tags located between the dial layer of the manometer and a metallic cover. At least two RFID tags need to be embedded under the shield layer to determine the measuring area of the manometer (green or red zone).

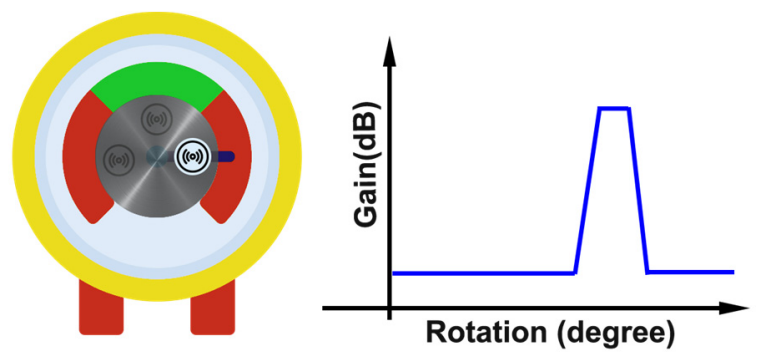

Figure 3. Analog manometer conceptual solution design.

\subsubsection{Analog Manometer Digitization Concept}

Analog manometers are widely used in industry to measure various physical parameters. Despite the diverse applications for which these manometers are designed, they all have similar mechanical mechanisms. The basic concept of this study was to implant small RFID tags on a single-side printed circuit board (PCB) FR4 substrate in analog manometers. The FR4 layer is placed on the manometer dial layer and covered with a metal cover to rotate with the manometer's pointer. The impact of cover addition weight on the manometer performance was neutralized by two offset adjustment screws inside the manometer. A circular opening in line with the pointer direction in metallic cover let EM waves pass to turn on the red or green zone RFID tag. A typical commercial RFID reader determines the manometer zone (green or red) by reading the tag's electronic product code (EPC) numbers.

\subsubsection{RFID Tag Design}

Commercial RFIDs in the $900 \mathrm{MHz}$ frequency band are usually designed in the size of a few centimeters. Many restrictions, including (i) lambda wavelength in this frequency band; (ii) limited sensitivity of RFID microchips; (iii) chip and antenna impedance matching, have made it impossible to reduce RFID tag dimensions smaller than a specific size. Engineers designing RFID tags for general use consider the optimal point between antenna size and antenna gain (which determines the reading range) [28]. For this reason, their dimensions are too large to be embedded in a manometer with a diameter of $100 \mathrm{~mm}$. Therefore, designing and simulating a new RFID tag with a tiny size preference was necessary. Despite 
their variety and diversity of uses, RFID tags all have fixed components that must be designed in perfect harmony with each other. The steps for creating an RFID tag are shown in Scheme 1 [29].

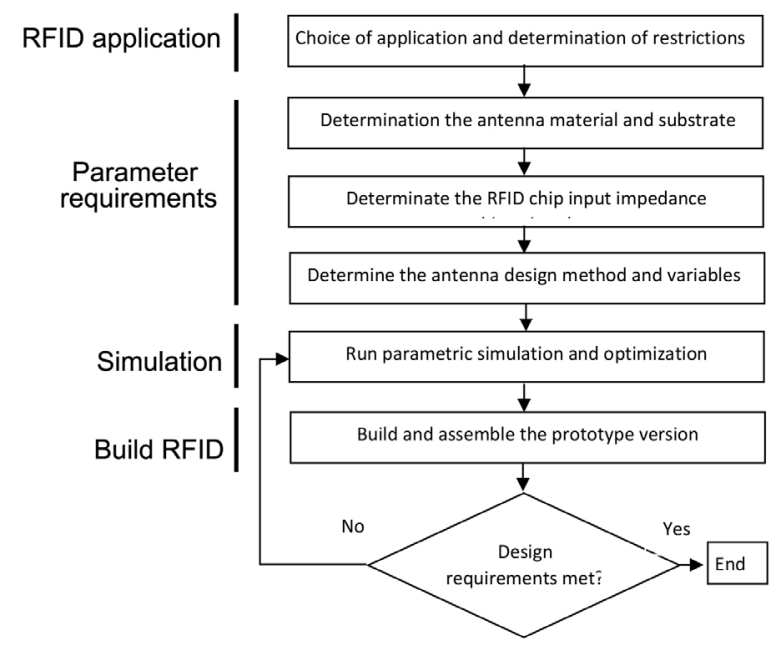

Scheme 1. RFID tag antenna design process.

Application Requirements and Restrictions

Frequency Band

RFID technology covers a wide bandwidth from $125 \mathrm{kHz}$ to $5.4 \mathrm{GHz}$. In the lowfrequency band, the antenna size increases due to the increase in wavelength, and the data transmission speed and reading range decrease. Despite the advantages of the highfrequency band, such as reducing the antenna size and increasing the speed and reading range, it is not an appropriate option for industrial environments due to reducing the penetration of EM waves in objects. Therefore, we have selected the $866 \mathrm{MHz}$ (midfrequency band), the most common frequency band in industry applications.

Antenna Pattern and Dimension Limitation

Bench test outputs showed that their RSSI chart pattern changed in two ways whenever the cover rotated and the tags exited the EM shield. Rectangular tags create an M-shaped pattern with two peaks, and square and circular tags create an A-shaped pattern with one maximum point. Therefore, due to the manometer shapes, the best option for our application was a circular dipole RFID tag. In terms of dimensions, manometers are designed and manufactured in less than one centimeter to several tens of centimeters. We chose the WIKA pressure gauge PGS21.100 as a case study for digitization. Detailed specification material and dimensions of the manometer are given in [30]. Due to the manometer dial plate limitation (94 $\mathrm{mm}$ diameter), we had to keep the RFID tag dimension under about $20 \mathrm{~mm}$. The green and red area tags were located at a distance of $\kappa /(8)$ from each other.

Antenna Material and Substrates

Choosing the suitable material and substrate is one of the most important parts of designing an RFID tag. As shown in Figure 4, the entire body of the manometer, except for the central part, is made of stainless steel. The RFID tags are all implanted on a standard single-layer FR4 PCB substrate with $1.6 \mathrm{~mm}$ of thickness coated with a $35 \mu \mathrm{m}$ thick copper layer as the RFID tag antenna. This layer is located directly on the dial plate. 


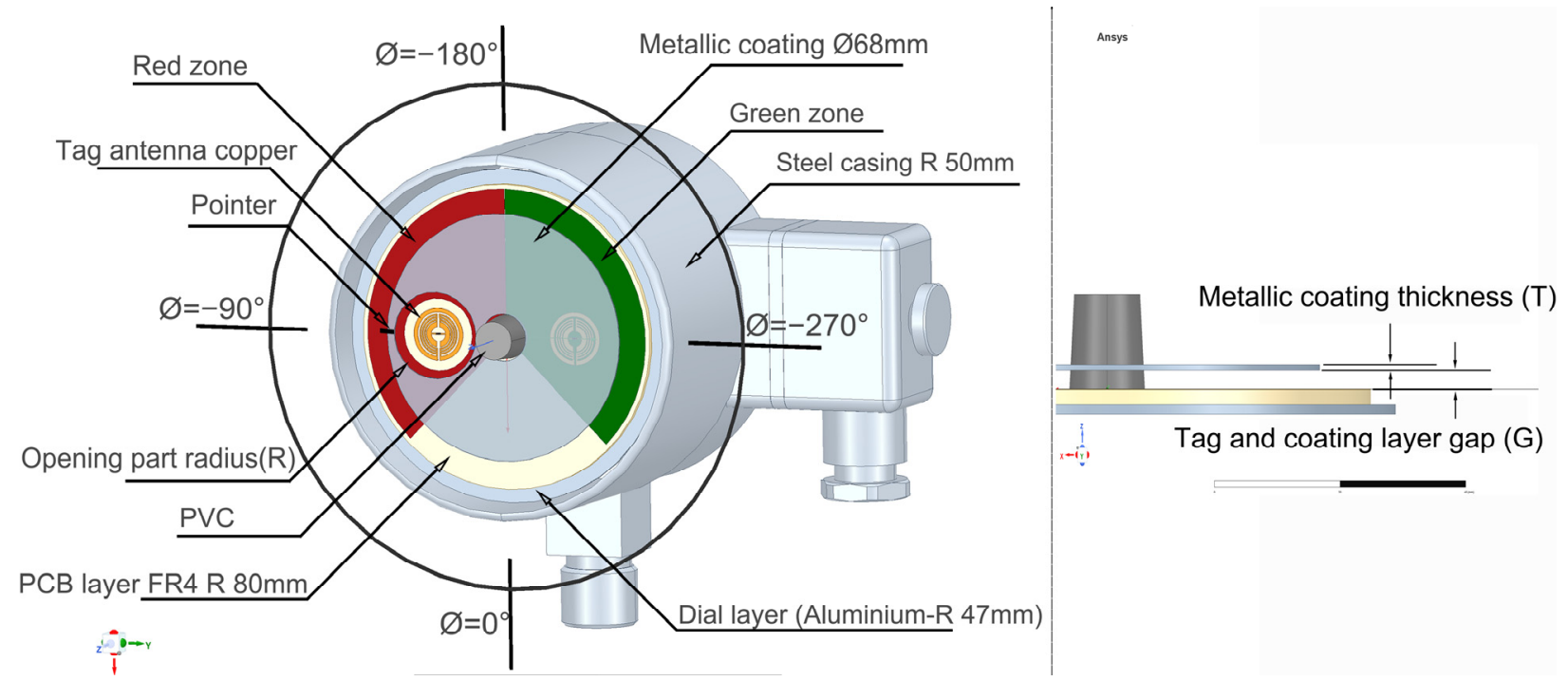

Figure 4. Digitized manometer components and materials.

RFID Chip Impedance Matching and Resistant

Numerous chips are designed and manufactured in the RFID frequency bands, but they are mostly not solderable and not available for commercial use in mass-production assembly lines. NXP UCODE G2iM is a series of passive identification transponder chips in the $900 \mathrm{Mhz}$ frequency band. UCODE G2iM SL3S1003 is a six-pin chip in the solderable SOT886 package [31], which provides $-17.5 \mathrm{dBm}$ read sensitivity. As shown in Figure 5, pins 1 and 3 are the RFP and RFN pins connected to the tag antenna, and pins 4 and 6 are the chip external battery pins (active mode configuration).



Figure 5. RFID tag Antenna and chip Geometry.

To transfer the maximum power absorbed by the tag antenna to the chip, the internal impedance of the designed antenna must be precisely equal to the conjugate input impedance of the chip. The higher the sensitivity and operating frequency of the tag, the 
more it allows the designer to design tags in smaller sizes. The internal impedance of the chips has a complex parameter that can be expressed as follows:

$$
Z_{c}=R_{c}+j X_{c} \cdot Z_{a}=R_{a}+j X_{a}
$$

The chip impedance $\left(Z_{c}\right)$ and antenna impedance $\left(Z_{a}\right)$ are both frequency-dependent and contain a real impedance part $(R)$ and complex impedance part $(X)$. The internal resistance table of the SL3S1003 chip in the frequency band is given in Table 2 [31]. Due to the European frequency band standard, the impedance of $866 \mathrm{MHz}$ in designing and tuning the tag antenna has been considered.

Table 2. SL3S1003 chip Input impedance.

\begin{tabular}{cccccc}
\hline Symbols & Parameter & Frequency & $\begin{array}{c}\text { Real } \\
\text { Part (R) }\end{array}$ & $\begin{array}{c}\text { Complex } \\
\text { Part (X) }\end{array}$ & Units \\
\hline \multirow{3}{*}{$Z$} & \multirow{2}{*}{ Impedance } & $866 \mathrm{MHz}$ & 27 & -234 & \multirow{2}{*}{$\Omega$} \\
\cline { 3 - 5 } & $915 \mathrm{MHz}$ & 24 & -222 & \multirow{2}{*}{} \\
\cline { 3 - 5 } & $953 \mathrm{MHz}$ & 23 & -213 & \\
\hline
\end{tabular}

\subsection{Electromagnetic Shielding Cover Simulation and Optimization}

EM isolation in the form of frequency shift and reduced transmission power can affect the proper functioning of the tags. For this reason, after adjusting all the parameters at the best point in the last section, we examine the effect of the metal plane in S11 and gain diagrams for a complete rotation of the metal cover. S11 is the most quoted parameter regarding antennas which represents how much power is reflected from the antenna and hence is known as the reflection coefficient. RFID antennas are two-way antennas (transmitter and receiver), and the gain diagram shows how well the waves are absorbed or propagated by the antenna. All simulation in this study was carried out with Ansys HFSS 2021 R2 software based on Finite Element Method (FEM) solver.

\section{Results}

This section presents the results of practical experiments and simulations in the following three sections:

- Isolation modeling results;

- RFID tag and isolator simulation results;

- Digitization simulation results.

The first part presents the modeling results of isolation and the effect of different metals and openings in EM isolation rate and its impact on RSSI parameters. The second part presents the simulation and tuning results of the designed RFID antenna. We sweep the $\mathrm{W}$ parameter (Figure 5) to adjust the resonant frequency of the embedded tag inside the manometer without an isolator cover. Then, we tune the whole manometer with the metallic cover at the optimum points. In the last section, we examined the performance of RFID tags in digitizing manometers (green and red zone detection) by simulating their gain changes.

\subsection{Experimental Test Bench Results}

The RSSI parameter changes were measured for the commercial tags against EM isolation. EM waves can reach the RFID antenna through circular openings in the metallic coating layer. 4Zerobox rotates the metallic layer to change the EM isolation rate and measure the RFID RSSI response via an RFID reader. The tests were performed in an environment without EM reflection to prevent the effects of unwanted noise on the outputs. The RSSI changes of each tag are examined against the EM isolation created by different metals, including stainless steel, galvanized steel, and iron (actually, it was AISI 304, a carbon steel used in sheet metalworking, but we use the label "Iron" to easily distinguish it 
from stainless steel). The isolation covers and circular opening made a different percentage of EM isolation for the tags. RSSI is shown in the separate curves in Figure 6, and the average change of all curves is given as a black line in charts. Metals cause different effects in the EM field, depending on their shape, thickness, density, and EM properties. The QTTM and H47 tags were both dual-dipole designs so that they could be read in any polarization without limiting the installation angle. The Impinj tag was a simple dipole with a rectangular antenna shape, leading to a different RSSI pattern with two peaks (M shape) against magnetic shielding. The maximum RSSI occurred when half of the tag was covered by metals (steps 2 and 4 in Figure 2b). The True 3D QTTM Long Reading tag had the highest amount of RSSI against various metals in an A-shaped pattern with a peak. The difference between the maximum and minimum RSSI in iron and stainless-steel diagrams was more significant than galvanized Steel.

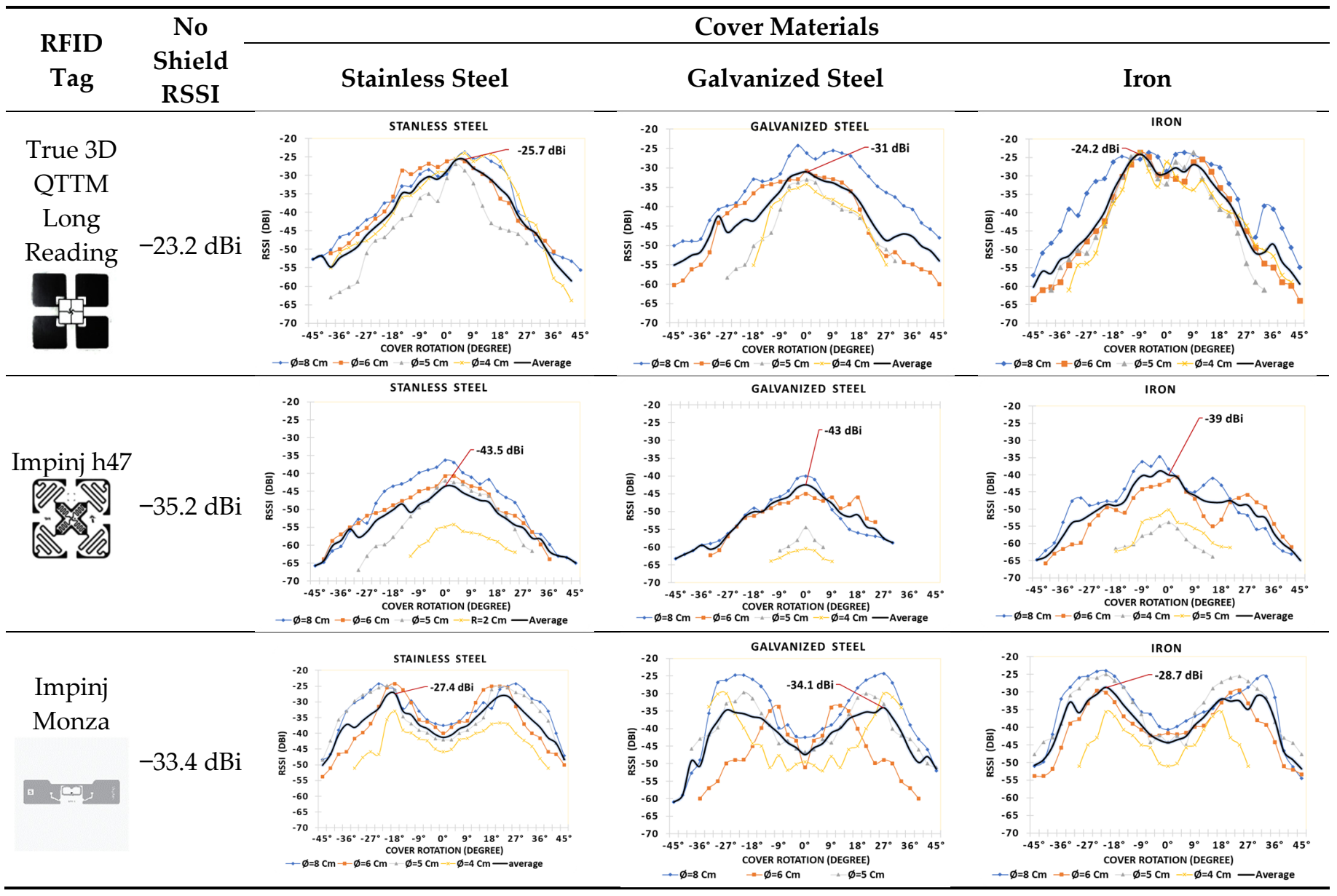

Figure 6. RSSI measured for RFID tags with different covering materials.

\subsection{RFID Tag and Isolator Simulation Results}

In Section 3.2, after explaining the reasons for designing a new RFID for embedding in the manometer, we described the designing steps and antenna geometry. In this step, to determine the dimensions of the antenna and adjust the parameters, we must first determine the parameters of the RFID tag by the EM wave simulator and then choose the metal cover parameters by embedding them in the manometer. Finally, by rotating the metal cover in 360 degrees cycles, we simulate the performance of the entire assembly against the EM field to digitize the manometer. 


\subsubsection{RFID Parametric Simulation}

In the next step, after determining and selecting the material and the initial geometry of the antenna to perform impedance matching, we should examine the parameters affecting the input resistance of the antenna and the S11 diagram. The optimal point of each variable was determined separately and in combination by EM simulation software and parametric simulation. Parameters D1- to D3 were static, and their dimensions were defined according to the size of the antenna port and RFID chip. The $\mathrm{H}$ parameter was also fixed due to the same thickness of the copper coating on the FR4 layer (about $35 \mu \mathrm{m}$ for FR4 $1 \mathrm{oz}$ ). Due to the limited size of the designed RFID tag described in Section Antenna Pattern and dimension limitation, $\mathrm{R}$ parameters were specified in some way to keep the tag dimension less than $20 \mathrm{~mm}$. Therefore, we tried to create the impedance matching by performing parametric analysis in only variables parameter $\mathrm{W}$. The cross-section area and distance of conductors are two critical components in determining the size of capacitors, inductors, and resistors. The sweep in the $\mathrm{W}$ parameter simultaneously leads to change in both these components. As a result, the impedance matching can be tuned accurately to the primary operating frequency $(900 \mathrm{MHz})$ by creating a frequency shift. The $\mathrm{W}$ parameter was swept in the range of 0.31-0.37 mm, and its effect in the S11 plot was investigated in Figure 7a. As shown in Figure 7b, the simulated input impedance at the UHF RFID central frequency is Zin $=10.3+j 234$. The electric field or " $E$ " plane shows the polarization or direction of the radio wave. The magnetic field or " $\mathrm{H}$ " plane lies at a right angle to the " $\mathrm{E}$ " plane. Co and cross-polarization in the $\mathrm{H}$ and $\mathrm{E}$ plan are shown in Figure $7 \mathrm{c}, \mathrm{d}$.



(a)

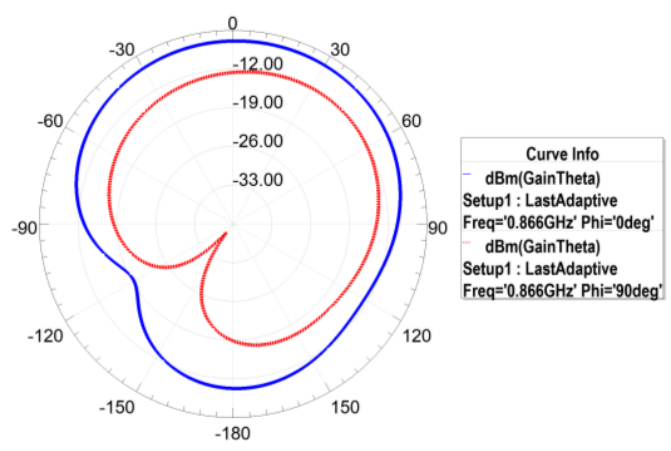

(c)

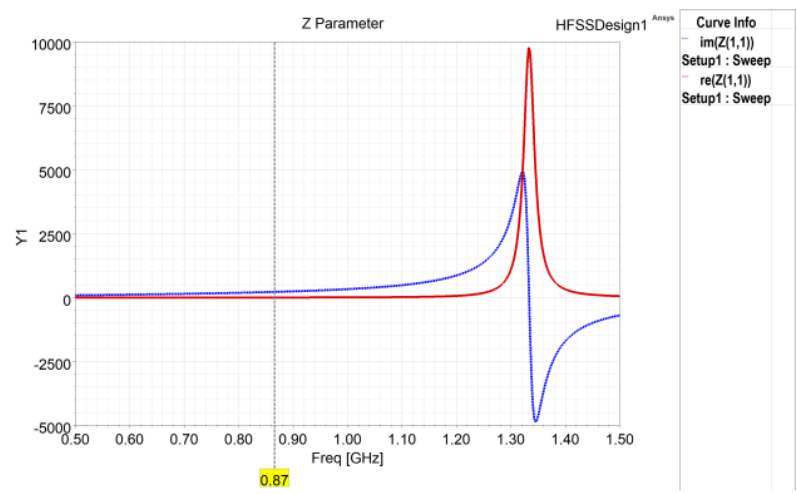

(b)

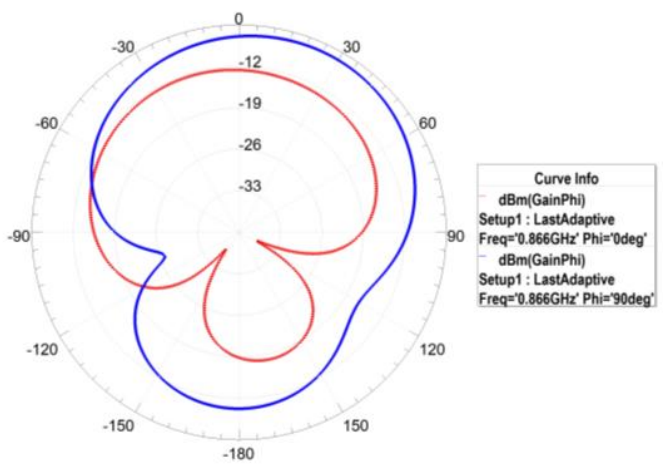

(d)

Figure 7. (a) Frequency tuning by sweeping W parameter; (b) antenna input impedance; (c) co-and cross-polarization of E plane (XZ plane); (d) co-and cross-polarization of $\mathrm{H}$ plane (YZ plane).

\subsubsection{Isolation Cover Parametric Simulation}

We tried to optimize the tag at the best working point in the previous step. In this step, we seek to optimize the metal cover to create the most damaging effect in the gain diagram and maximize the difference in both the gain graphs of shielded and non-shielded modes. Eventually, this difference in gain will cause the tags to be turned on or off by moving the 
manometer's pointer. According to the measurements made in the bench test, we expected that the EM shield coating would eliminate the frequency matching by creating a frequency shift. It would be led to reducing the power transfer received by the tag antenna to the chip and eventually causing the chip to turn off. Therefore, after adding the metallic cover step by step, each parameter is checked by rotating the cover in two modes: $\varnothing=0^{\circ}$ (the tag is covered) and $\varnothing=-90^{\circ}$ (the tag is not covered). The ultimate goal is to create the highest significant possible difference in the gain of the RFID tag in 2 cases when the cover angle is $0^{\circ}$ and uncovered at $-90^{\circ}$ (Figure 4 ).

\section{RFID Tag and Cover Gap}

The first parameter that was examined after adding the cover was the distance between the RFID tag and the EM cover, which was simulated as a hybrid parametric simulation at the same time as the cover was rotated. According to the results shown in Figure $8 \mathrm{a}$, the smaller the gap between the tag and the metallic cover led to the more significant the difference in RFID gain between covered and without cover conditions (the best case is the enormous difference), which creates a difference of about $19 \mathrm{dBm}$ in RFID gain. Therefore, according to the dimensions of the RFID tag chip, a distance of $0.15 \mathrm{~mm}$ was determined as the optimal distance.



(a)
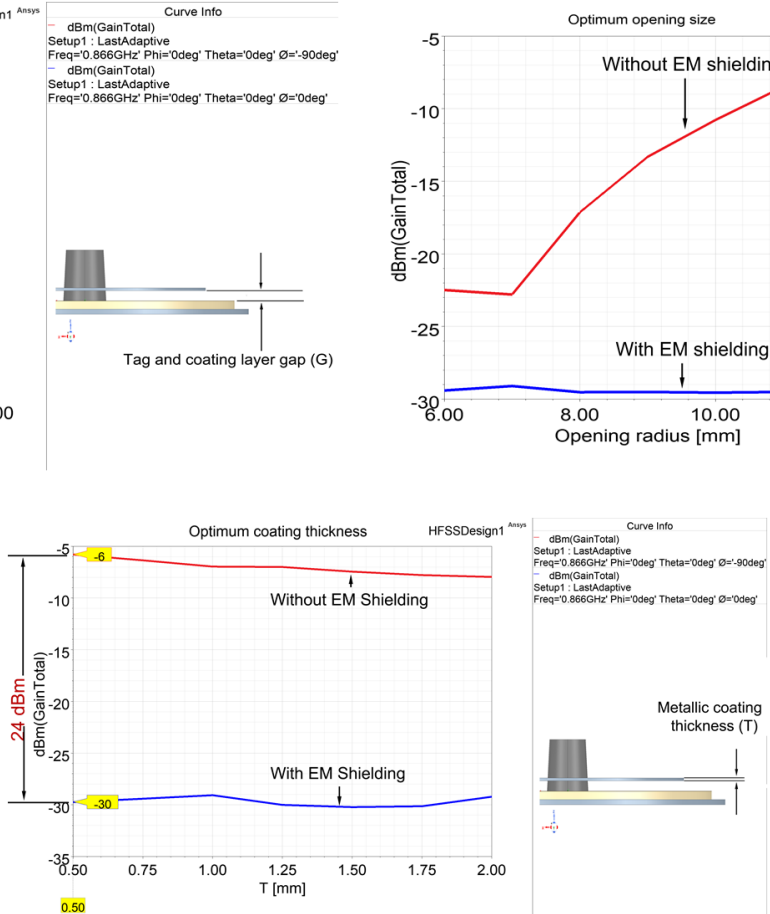

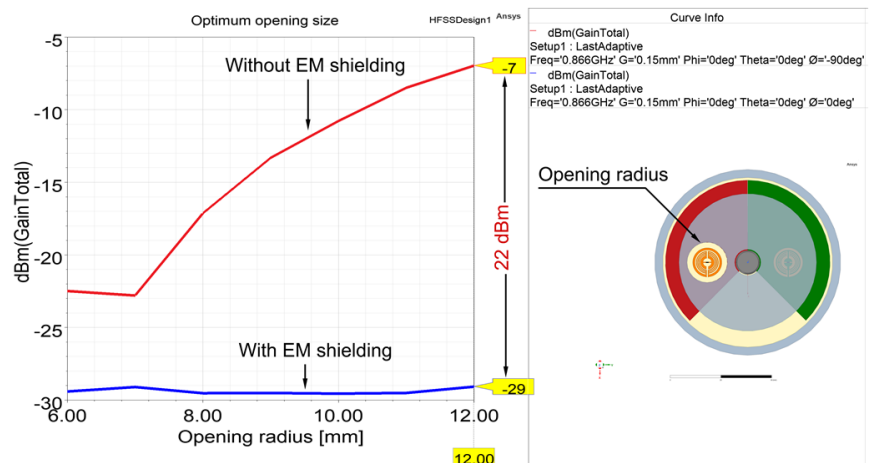

(b)

(c)

Figure 8. Metallic EM shield cover tuning parameters. (a) The optimal point of tag and cover gap; (b) the optimal point of the cover opening part radius; (c) the Optimal point of electromagnetic cover thickness.

\section{Cover Opening Part Size}

Based on the bench test results, it emerged that the RSSI rate improved with increasing the diameter of the cover opening part, the dimensions of the opening part would have a substantial effect on the amount of tag received gain. For this reason, we simulated this parameter in combination with the rotation of the EM cover. The results of the cover opening radius sweeping in the range of 6 to $12 \mathrm{~mm}$ are shown in Figure 8b. As expected, the larger opening size increased the gain of the tag when the tag was not covered $\left(\varnothing=-90^{\circ}\right)$. Due to the size limitation, we considered the maximum possible size of opening radius (12 $\mathrm{mm}$ ) 
for the opening part. This opening size increases the difference gain (with and without cover) from $19 \mathrm{dBm}$ to $22 \mathrm{dBm}$.

\section{Isolation Cover Thickness}

In the last step, we investigated the thickness of the EM shield cover and the effects of this parameter on the output gain by parametric simulation. Figure $8 \mathrm{c}$ shows the sweep results of this parameter from 0.5 to $2 \mathrm{~mm}$. The results clearly show that the thickness of the protective layer does not have a significant effect on the gain of the RFID tag, so we consider its minimum value of $0.5 \mathrm{~mm}$ as the optimal point.

\subsection{Digitization Simulation Results}

\subsubsection{Metallic Isolation Effect on the Reflection Coefficient}

After optimizing all the variables of the RFID tag and the magnetic cover separately and determining all the parameters, we can simulate the whole set with a combined simulation and examine the result of adding an EM shield. For this purpose, we must examine the reflection coefficient (or S11 parameter) in the total bandwidth at two angles $\varnothing=0^{\circ}$ (EM isolated) and $\varnothing=-90^{\circ}$ (without electromagnetic isolation). As shown in Figure 9, rotation of the electromagnetic cover creates a frequency shift of about $300 \mathrm{MHz}$ in the S11 diagram. The bandwidth was reduced from $0.46 \mathrm{MHz}$ to $0.26 \mathrm{MHz}$ after creating the magnetic shield so that there is no overlap bandwidth between the two graphs.

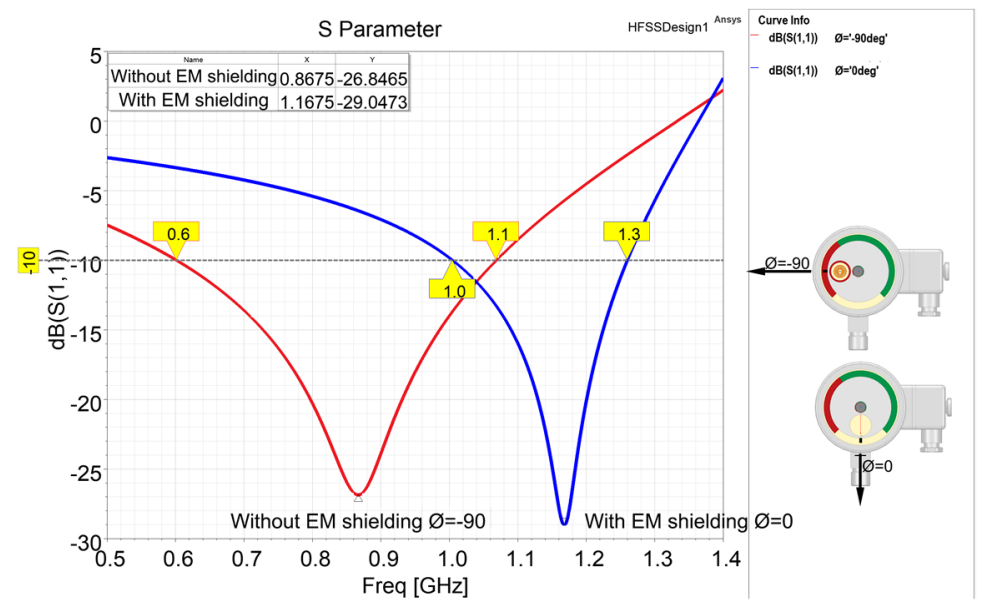

Figure 9. Electromagnetic isolation impact on S11 grape.

\subsubsection{RFIDs Total Gain and Digitization}

After tuning all the effective parameters in the RFID tag and the insulation cover layer, we can now check the performance of the tags embedded in the manometer. For this purpose, we measure the total gain changes of both tags in a complete rotation of the metallic cover. As shown in Figure 4, the red zone tag was mounted at $\varnothing=-90^{\circ}$, and the green zone tag was mounted at $\varnothing=-270^{\circ}$ manometers. By rotating the metal cover, the EM waves reached the tags from the opening part and caused them to be read by the RFID reader. This gain increased in 2 intervals of $100^{\circ}$ degrees to the center of angles $-90^{\circ}$ and $-270^{\circ}$ (Figure 10). 


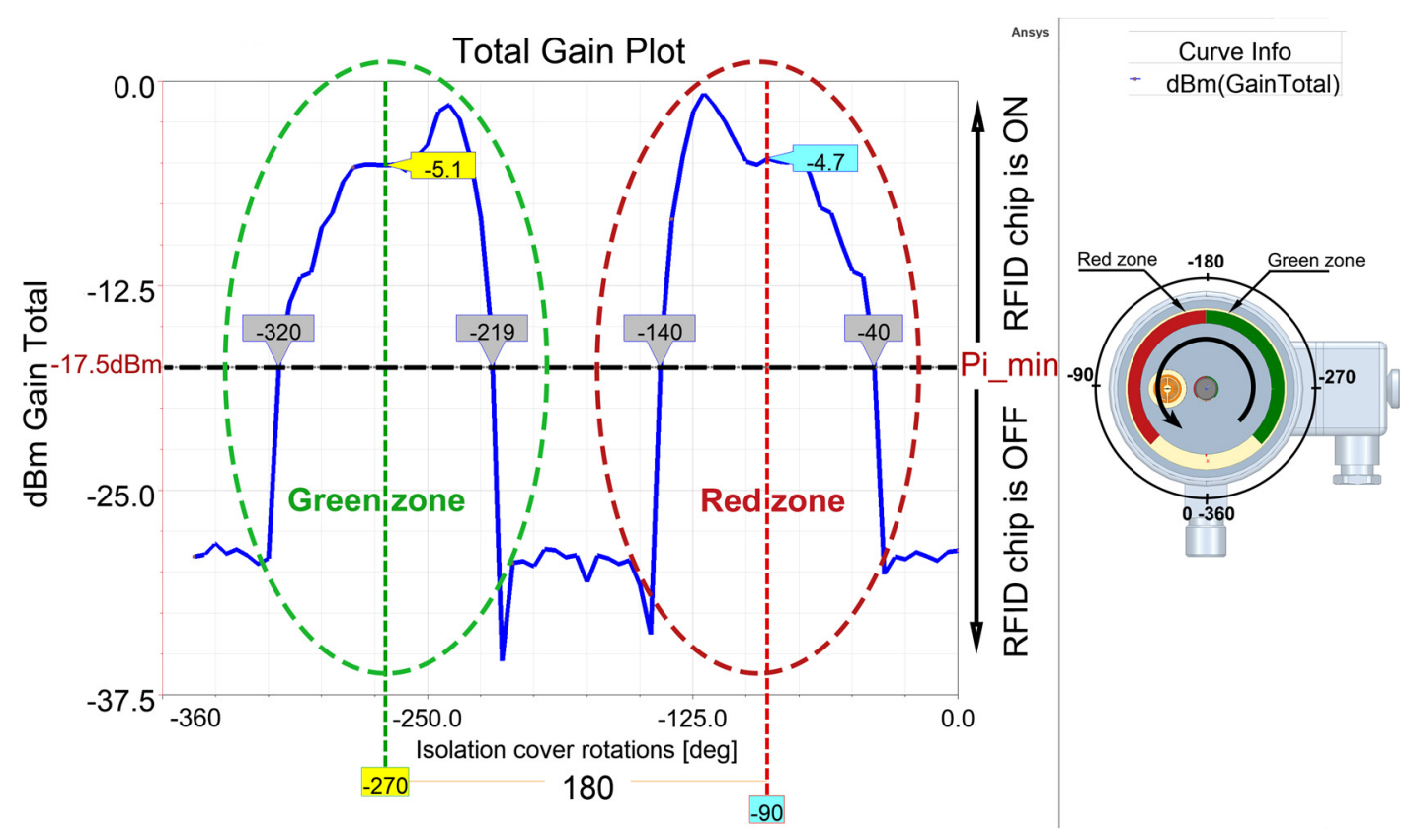

Figure 10. RFID tag total gain and switching angles.

\section{Discussion}

The metallic covers and parasitic elements cause EM isolation for the RFID tags. Nearfield metal covers create an inductive and capacitive coupling that changes the antenna's input impedance. Chip and antenna impedance mismatch causes only a tiny portion of the absorbed energy to be transferred to the chip. If the energy transferred to the chip is less than the $P_{\text {imin }}$, it leads to turning off the chip. $P_{\text {imin }}$ or reading sensitivity means the minimum input power of the chip to turn it on. NXP states that this parameter is $-17.5 \mathrm{dBm}$ in SL3s1003, which means that the chip is off as long as the power gain chart is below this value [31]. The intersection of this line $(-17.5 \mathrm{dBm})$ with the gain diagram in Figure 10 shows that the red tag from $\varnothing=-40^{\circ}$ to $-140^{\circ}$ and the green tag from $\varnothing=-219^{\circ}$ to $-320^{\circ}$ are clear readable for the RFID reader. To better understand the performance of the tags and switching points, Figure 11 shows the trigger angles during a 360-degree rotation of the manometer pointer. The locating of the manometer pointer in each zone (red or green) leads to only activating the same zone tag, and the RFID reader easily determines the zone through the EPC code of the chips. In this way, thanks to RFID technology and the EM isolation effect as an advantage, we introduced a method to digitize manometer passively and wirelessly.

Such an integrated passive RFID tag and the metallic cover allow the manometer to be easily read by already installed RFID readers or by installing an antenna on movable objects (e.g., forklifts, bicycles often used in large industrial plants, or even in the industrial cleaning trolleys), thus reducing the necessary number of readers. The study demonstrated the feasibility of a Passive RFID tag and EM isolation to retrofit industrial analogical devices such as manometers, handwheels, etc., in an effective and low-cost way. 




Figure 11. Digitized Analog manometer.

Author Contributions: Conceptualization, G.F.; methodology, G.F. and S.A.; software, M.H.; validation, G.F. and A.M.; formal analysis, M.H.; investigation, M.H. and S.A.; resources, A.M.; data curation, G.F.; writing-original draft preparation, M.H. and S.A.; writing—review and editing, A.M.; visualization, A.M.; supervision, A.M.; project administration, G.F.; funding acquisition, G.F. All authors have read and agreed to the published version of the manuscript.

Funding: This research work was undertaken in the context of DIGIMAN4.0 project ("DIGItal MANufacturing Technologies for Zero-defect Industry 4.0 Production", http:/ / www.digiman4-0 .mek.dtu.dk/, accessed on 21 July 2021). DIGIMAN4.0 is a European Training Network supported by Horizon 2020, the EU Framework Program for Research and Innovation (Project ID: 814225).

Institutional Review Board Statement: Not applicable.

Informed Consent Statement: Not applicable.

Data Availability Statement: Not applicable.

Acknowledgments: The authors express their gratitude to the anonymous reviewers for their valuable comments that helped us to improve the paper significantly.

Conflicts of Interest: The authors declare no conflict of interest.

\section{References}

1. Varriale, V.; Cammarano, A.; Michelino, F.; Caputo, M. Sustainable Supply Chains with Blockchain, IoT and RFID: A Simulation on Order Management. Sustainability 2021, 13, 6372. [CrossRef]

2. $\quad$ Stark, R.; Damerau, T.; Chatti, S. Digital twin. CIRP Encycl. Prod. Eng. 2019, 66, 1-8.

3. DIN SPEC 91345: Reference Architecture Model Industrie 4.0 (RAMI4. 0); DIN: Berlin, Germany, 2016; Volume 4, p. 2016.

4. Cook, B.S.; Vyas, R.; Kim, S.; Thai, T.; Le, T.; Traille, A.; Aubert, H.; Tentzeris, M. RFID-based sensors for zero-power autonomous wireless sensor networks. IEEE Sens. J. 2014, 14, 2419-2431. [CrossRef]

5. Dimitriou, A.G.; Bletsas, A.; Sahalos, J.N. Room-coverage improvements in UHF RFID with commodity hardware [wireless corner]. IEEE Antennas Propag. Mag. 2011, 53, 175-194. [CrossRef]

6. Zhong, R.Y.; Dai, Q.Y.; Qu, T.; Hu, G.J.; Huang, G.Q. RFID-enabled real-time manufacturing execution system for masscustomization production. Robot. Comput.-Integr. Manuf. 2013, 29, 283-292. [CrossRef]

7. Ramirez, R.A.; Rojas-Nastrucci, E.A.; Weller, T.M. UHF RFID tags for on-/off-metal applications fabricated using additive manufacturing. IEEE Antennas Wirel. Propag. Lett. 2017, 16, 1635-1638. [CrossRef]

8. Ghahremani, A.; Rezaei, V.D.; Bakhtiar, M.S. A UHF-RFID transceiver with a blocker-canceller feedback and $+30 \mathrm{dBm}$ output power. IEEE Trans. Circuits Syst. I 2013, 60, 3043-3054. [CrossRef]

9. Michel, A.; Franchina, V.; Nepa, P.; Salvatore, A. A UHF RFID Tag Embeddable in Small Metal Cavities. IEEE Trans. Antennas Propag. 2019, 67, 1374-1379. [CrossRef] 
10. Pino, M.R.; Michel, A.; Narciandi, G.A.; Nepa, P. Read-Range Estimation of UHF-RFID Tags Placed Inside Metal Pipes. In Proceedings of the 2019 13th European Conference on Antennas and Propagation (EuCAP), Krakow, Poland, 31 March-5 April 2019.

11. Arora, K.; Mallinson, H.; Kulkarni, A.; Brusey, J.; McFarlane, D. The practical feasibility of using RFID in a metal environment. In Proceedings of the 2007 IEEE Wireless Communications and Networking Conference, Shanghai, China, 21-25 September 2007; IEEE: Shanghai, China, 2007.

12. Tuyishime, C.R.; Nzanywayingoma, F.; Gatera, O. IoT-based Intelligent Energy Efficiency Management System for Smart Industries (IoT-IEEMS). In Proceedings of the 2021 IEEE International Conference on Industry 4.0, Artificial Intelligence, and Communications Technology (IAICT), Bali, Indonesia, 27-28 July 2021; IEEE: Bali, Indonesia, 2021.

13. Hänel, T.; Brüggemann, L.; Loske, F.; Aschenbruck, N. Long-Term Wireless Sensor Network Deployments in Industry and Office Scenarios. In Proceedings of the 2021 IEEE 22nd International Symposium on a World of Wireless, Mobile and Multimedia Networks (WoWMoM), Pisa, Italy, 7-11 June 2021; IEEE: Pisa, Italy, 2021.

14. Nideborn, J. Industrial Network Market Shares 2015-2021; Hardware Meets Software (HMS) Group: Halmstad, Sweden.

15. Cheng, Y.J.; Chen, M.H.; Cheng, F.C.; Cheng, Y.C.; Lin, Y.S.; Yang, C.J. Developing a decision support system (DSS) for a dental manufacturing production line based on data mining. Appl. Syst. Innov. 2018, 1, 17. [CrossRef]

16. Michalski, A.; Watral, Z. Problems of Powering End Devices in Wireless Networks of the Internet of Things. Energies 2021, 14, 2417. [CrossRef]

17. Neal, A.D.; Sharpe, R.G.; van Lopik, K.; Tribe, J.; Goodall, P.; Lugo, H.; Segura-Velandia, D.; Conway, P.; Jackson, L.M.; Jackson, T.W.; et al. The potential of industry 4.0 Cyber Physical System to improve quality assurance: An automotive case study for wash monitoring of returnable transit items. CIRP J. Manuf. Sci. Technol. 2021, 32, 461-475. [CrossRef]

18. Vagaš, M.; Galajdová, A.; Šimšík, D.; Onofrejová, D. Wireless data acquisition from automated workplaces based on RFID technology. IFAC-PapersOnLine 2019, 52, 299-304. [CrossRef]

19. Chen, S.-L.; Kuo, S.-K.; Lin, C.-T. A metallic RFID tag design for steel-bar and wire-rod management application in the steel industry. Prog. Electromagn. Res. 2009, 91, 195-212. [CrossRef]

20. CEN, EN 837-1:1996/AC:1998 Pressure Gauges—Part 1: Bourdon Tube Pressure Gauges—Dimensions, Metrology, Requirements and Testing. 11 June 1998, p. 24. Available online: https://standards.iteh.ai/catalog/standards/cen/812a8aab-49be-4466-9113428d36d4543e/en-837-1-1996-ac-1998 (accessed on 20 October 2021).

21. Kim, J.; Yoon, H.; Park, J.; Burm, J. A method to improve isolation for RFID applications. In Proceedings of the 2005 European Microwave Conference, Paris, France, 4-6 October 2005; IEEE: Paris, France, 2005.

22. Loo, C.H.; Elsherbeni, A.Z.; Yang, F.; Kajfez, D. Experimental and simulation investigation of RFID blind spots. J. Electromagn. Waves Appl. 2009, 23, 747-760. [CrossRef]

23. Buffi, A.; Michel, A.; Nepa, P.; Tellini, B. RSSI measurements for RFID tag classification in smart storage systems. IEEE Trans. Instrum. Measur. 2018, 67, 894-904. [CrossRef]

24. Shen, L.; Zhang, Q.; Pang, J.; Xu, H.; Li, P.; Xue, D. ANTspin: Efficient Absolute Localization Method of RFID Tags via Spinning Antenna. Sensors 2019, 19, 2194. [CrossRef] [PubMed]

25. Babar, A.A.; Bjorninen, T.; Bhagavati, V.A.; Sydanheimo, L.; Kallio, P.; Ukkonen, L. Small and Flexible Metal Mountable Passive UHF RFID Tag on High-Dielectric Polymer-Ceramic Composite Substrate. IEEE Antennas Wirel. Propag. Lett. 2012, 11, 1319-1322. [CrossRef]

26. Chen, S.-L.; Lin, K.-H. A slim RFID tag antenna design for metallic object applications. IEEE Antennas Wirel. Propag. Lett. 2008, 7, 729-732. [CrossRef]

27. Mazzei, D.; Montelisciani, G.; Baldi, G.; Baù, A.; Cipriani, M.; Fantoni, G. Improving the Efficiency of Industrial Processes with a Plug and Play Iot Data Acquisition Platform. In Enterprise Interoperability: Smart Services and Business Impact of Enterprise Interoperability; Wiley Online Library: Hoboken, NJ, USA, 2018; pp. 315-321.

28. Marrocco, G. The art of UHF RFID antenna design: Impedance-matching and size-reduction techniques. IEEE Antennas Propag. Mag. 2008, 50, 66-79. [CrossRef]

29. Rao, K.S.; Nikitin, P.V.; Lam, S.F. Antenna design for UHF RFID tags: A review and a practical application. IEEE Trans. Antennas Propag. 2005, 53, 3870-3876. [CrossRef]

30. Alexander Wiegand WIKA. Bourdon Tube Pressure Gauge with Switch Contacts Stainless Steel Case, NS 100 and 160 Models PGS21.100 and PGS21.160. 2020, p. 12. Available online: https://www.wika.com/en-en/pgs21_100_pgs21_160.WIKA (accessed on 28 December 2021).

31. NXP Semiconductors. SL3S1003_1013 UCODE G2iM and G2iM+, NXP, Editor. 5 February 2019, p. 47. Available online: https://www.nxp.com/docs/en/data-sheet/SL3S1003_1013.pdf (accessed on 28 December 2021). 